\title{
Sustainable ICT: A Critique from the Perspective of World Systems Theory
}

\author{
Thomas Taro Lennerfors, Per Fors, and Jolanda van Rooijen \\ Dept. of Engineering Sciences, \\ Div. of Industrial Engineering and Management, \\ Uppsala, Sweden \\ \{thomas.lennerfors, per.fors, jolanda.van.rooijen\} @angstrom.uu.se
}

\begin{abstract}
Even though the ICT (Information and Communication Technology) industry has historically been spared the critique of being environmentally unfriendly, society has as of late recognised the negative environmental effects of the ICT industry. However, such critique has been gradually replaced by the concept of Sustainable ICT, in which ICT is almost seen as a saviour, something with big potential of solving economic, societal and environmental issues. In this paper, our aim is to critically discuss the notion of Sustainable ICT by turning to an ecological perspective of World Systems Theory (WST). Immanuel Wallerstein, the main proponent of WST argues that the success of developed (core) countries today is a product of systematic unequal exchange of raw material, goods and labour with underdeveloped (peripheral) countries. Alf Hornborg, the Swedish Marxist ecologist, develops WST by focusing on the global distribution of environmental degradation. In this paper, we present Hornborg's ecological WST, we apply it to ICT by means of examples from the ICT Value Chain (from materials extraction to disposal) in order to illustrate the global distribution of environmental degradation. We argue that WST is a fruitful, and critical, alternative perspective to the more optimistic view of Sustainable ICT.
\end{abstract}

\section{Introduction}

Even though the ICT industry has historically been spared the critique of being environmentally unfriendly, society has as of late recognized the negative environmental effects of ICT industry. Reports have shown that almost $2 \%$ of the total greenhouse gas emissions worldwide occur due to the usage of ICT equipment [1], and the increasing number of large data centres consume considerable amounts of energy. Furthermore, the ICT sector is a growth sector, and it has been calculated that by 2020 , the total GHG emissions from mobile data traffic might be three times higher than today [2], and that this will be a much larger problem than the energy intensive data centers in the future [3]. There are also several other environmental and social implications in connection with the ICT sector, such as the production of e-waste, the extraction of rare earth elements (REEs) and conflict minerals and the sometimes hazardous production of the equipment. 
The general perception within the field today is that even though ICT has a big negative impact on the environment, it has probably an even greater potential in improving the environment by mitigating the environmental impact of other emission processes such as production, agriculture and transportation [1]. One simple Internet search with keywords such as "ICT" and "environment" combined, will tell the same story. Smart ICT solutions will potentially be able to decrease the annual GHG emissions by $9,1 \mathrm{GtCO}_{2} \mathrm{e}$ worldwide, as well as creating 29,5 million jobs and save USD 1,9 trillion for consumers and businesses [1]. Even though we agree that there are many positive aspects of ICT, we would like to apply a more critical perspective to the relationship between ICT and sustainability than that of Sustainable ICT.

In this paper, our aim is to critically discuss the notion of Sustainable ICT by turning to an ecological perspective of World Systems Theory [4,5,6]. By doing so, we want to open up a discussion about how Sustainable ICT and its predecessors contribute to ecological sustainability on a global scale. We argue that even though conditions in developed, core countries may be improved by the increased usage of sustainable ICT solutions, most of these improvements are made possible because of environmental and social degradation in peripheral, developing zones. Even though we do not claim this to be an entirely new insight, nor that we are able to prove that ecological effects of ICT are distributed unequally, we advance the claim that World Systems Theory is an important theoretical framework for discussing ICT, especially in the society of today where ICT is seen as one of many solutions to a range of economic, societal and environmental problems. A quite recent review of research on the environmental impact of ICT indeed confirms that a model-based approach is needed to allow "that positive effects can be promoted and negative ones alleviated proactively" [8]. World Systems Theory might be such model.

\subsection{Outline of the Paper}

In the second part of the paper, we will discuss Sustainable ICT and World Systems Theory (WST), and its ecologically aware versions. In this part, we will also review how WST has been applied to studies of ICTs in the past. In the third part we discuss the ICT value chain from material extraction to disposal. We present a number of examples and tentatively analyse these examples from the point of view of WST. In the fourth part, we summarize our main findings.

\section{Sustainable ICT and World Systems Theory}

\subsection{From Green Computing to Sustainable ICT}

As we have stated in the introduction, ICT has historically been spared of critique of being environmentally unfriendly, although recently concerns about energy use coupled with the growing use of ICT, and the increasing production of e-waste have been raised $[1,2,9]$. Certainly, there are positive environmental aspects of ICT as well and we would like to think about the discourse of positive environmental aspects of ICT as consisting of three phases - Green Computing, Green IT, and Sustainable ICT. 
In the 1990s, under the label of Green Computing, the U.S. Environmental Protection Agency launched the voluntary program Energy Star, which is an energy-efficiency certification for electronic devices, mainly seen on old CRT monitors. Several other similar concepts emerged during the same time period, emphasising energy-efficiency as well as sustainable production and recycling of ICT equipment and other electronic devices (i.e. EPEAT, TCO certification). The focus in this phase was on the environmental aspects of the ICT devices in themselves. This was going to change.

In 2007, the discourse once again emphasised sustainable ICT practices, now under the concept of Green IT. Gartner Institutes launched a report in 2007, which showed that around $2 \%$ of the total energy consumption of Britain was due to the usage of ICT equipment. This was almost as much as the airline industry. Therefore, it became important to think about the greening of ICT. The difference between Green Computing and Green IT was that within Green IT, ICT was not only seen as the villain of the environmental issues, but more importantly a part of the solution [10]. The practices of Green Computing turned into greening of IT while the part of the concept where ICT could be the solution was called greening by IT. Greening of IT is thus not as focused on the ICT equipment, but rather focus on the beneficial potential of ICT applications Many argued that while Greening of IT did have some impact on sustainability, Greening by IT was even more important. The main argument presented was that while Greening of IT can only address $2 \%$ of the potential of Green IT, greening by IT could help streamlining other parts of the organisation by "smart" solutions, such as route planning, web meetings and virtualisation of servers, dematerialisation, in the remaining $98 \%$. To sum up, the discourse on Green IT, although it started as a renewed concern with the amounts of energy consumed by ICT equipment (referring to the Gartner report), it got more and more focused on Greening by IT. It is plausible that a focus on Greening of IT, leads to further penetration of ICT into different societal sectors.

While the discussion of the positive impact of ICT was brought up by the discussion about Green IT from 2007, a burgeoning development, something we call the third wave in this field, is Sustainable ICT. In Sustainable ICT, economical and societal are added to the environmental concerns of green IT and green computing. Sustainable ICT focuses more on the "greening by" practices of green IT, while adding what IT can contribute with economically and socially. According to Harmond and Demirkan [11], this wave of sustainable computing will require organisations to consider "environmental (ecological and regulatory), social (ethical and philantropic) and economic strategies while delivering on core IT performance requirements to drive business productivity" [11, p. 19]. The same article argues that "sustainability has emerged as a business megatrend that fundamentally impacts how business compete" $[11$, p. 20].

During this whole development, a broadening of the scope has occurred, from the view of Green Computing, where we have to use ICT equipment more carefully and more efficiently, to Sustainable ICT, where ICT has a big potential of solving economic, societal and environmental issues. Above all, sustainability in general is described as a business strategy, used in order to gain market advantages. Yet another general direction in the development of the discourse on ICT is that it is turning increasingly optimistic. 


\subsection{World Systems Theory}

The idea of World Systems Theory was created during the 1970s as a way to develop the Marxian tradition of social studies [12]. The theory is mainly based on the ideas of Karl Marx and Rosa Luxemburg. Rather than to discuss the class conflicts within a particular country, World Systems Theory discusses inequalities on a global level [13]. The reason for this broadening of the scope is due to Rosa Luxemburg's important remark that capitalism cannot be contained in itself, but must expand geographically in order to survive and prosper [14, p. 36]. In other words, instead of addressing the exploitation of the working class by the capitalists, Wallerstein discusses exploitation by inventing two key concepts - the core and the periphery. The core is basically the developed, rich countries, while the periphery is the poor countries, receiving a disproportionately small portion of the global wealth. The main argument in World Systems Theory is that the core countries exploit the "underdeveloped" countries by placing them on the outer edges of global trade. Wallerstein argues that the success of developed countries today is a product of systematic unequal exchange of raw material, goods and labour with developing countries. The exploitation of the periphery, from the point of view of WST, started during the age of colonisation and still exists in terms of trade between core and peripheral countries that constantly favour the core. The prosperity of core zones is thus not possible without the exploitation of peripheral zones, according to Wallerstein, just as the capital accumulation process of production is not possible without the exploitation of labour power of the working class in a Marxian analysis. Apart from core and peripheral regions, there are also semi-peripheries that are not as privileged as the core zones, but also not as exploited as the peripheral zones. Wallerstein's analyses of world systems often revolve around economic and, as an extension of economic effects, social effects of the unequal exchange between the core and the periphery.

Alf Hornborg, the Swedish Marxist ecologist, while being inspired by traditional WST, has developed WST in several ways. His focus is not only economic and social (addressing the economic relationship between the core and the periphery, and exploring its social effects), but more importantly environmental. In his analysis of world systems, the notion of emergy is vital [14]. Emergy is a measure of how much energy that has been consumed in order to create a product or an organism. When natural resources such as coal, oil and iron are extracted from the earth, the contribution of the natural processes (i.e. geothermal processes) to the emergy value of the resources are often neglected. According to Odum and Arding [15], the reason for this is because we see natural resources as "free gifts of nature" and misconceive their true value. The labour cost for extracting these resources are however being accounted for but, according to WST, at too low a price. The undervaluation of the price of natural resources, mainly extracted in peripheral areas, is one great contributor to why the core-periphery relation is still retained.

Not only are the natural resources unequally distributed by this relation, but also the environmental effects that the usage of these resources leads to. This is what Hornborg entitles the "global distribution of environmental degradation" [14] and is his greatest contribution to the theory. This assumption is based on that our world is a 
closed material system, a zero-sum game, and not a cornucopian world where resources are unlimited. This means that improvements in one part of the world system is always offset by deterioration in other parts of the world system. When natural resources are used by the core to increase the standard of living in the developed parts of the world, the periphery suffers the environmental and social consequences. The unequal exchange of resources allows the core to afford extensive investments in ICT solutions ("accumulation of technomass"), making their organizations more economically efficient, while at the same time improving the work environment as well as lowering emissions of greenhouse gases directly from the core zones. This has some implications for sustainability and ICT, because the extensive usage of ICT in the core have social and environmental implications elsewhere, somewhere along the value chain of the required ICT equipment. Even though infotization is a major trend in world, world system theorists have been rather silent upon issues relating to ICT. There are however some important contributions, reviewed in the next section.

\subsection{World Systems Theory and ICT}

Konieczny [16] argues that all early ICTs such as printing technologies, the telegraph, the telephone, radio and television were all invented, developed and deployed in the core, which means that the core "had decades if not centuries of near monopoly on their use" [16, p. 260]. He argues that the case of the Internet is not different. Beginning as a US military project, the Internet relies on expensive technology and skills that are hard to come by in the periphery. However, while there are WST inspired debates about the digital divide, there are also important positive effects identified by World Systems Theorists. While traditionally having been used mainly by Western core countries, the number of Chinese users is increasing dramatically. In mid-2004, English speakers constituted 36 percent of Internet users, while Chinese users constituted 13 percent. 5 years later, the English accounted for 28 percent of the Internet population, while the Chinese accounted for 23 percent. Konieczny thereby notes how the Internet indeed harbors potential for a more just and equitable use of information technologies.

Writing about the ICT equipment from a WST perspective, Nelson-Richards et al. [17] show how core countries invest heavily in ICT and that investments in ICT lead to higher productivity and business performance, which is to be expected. This displays that they are now knowledgeable of the productivity paradox of ICT, which would imply that the core distances itself from the periphery.

Lawrence [18] discusses the intersection between energy use and WST. There is a strong positive correlation between energy use and a country's position in the world system. The semi-periphery, such as China, uses more energy and produces more emissions, while the periphery has seen energy and emissions increase but to a lower extent than the semi-periphery.

Smith, Sonnenfeld and Pellow [19] are portraying the negative environmental and social effects of the production of the latest high-tech gadgets. They focus on the US and on the emergence of the high-tech industry in what was going to become the Silicon Valley in the 1980s. Sonnenfeld argues in the same book that "[h]ierarchies of 
power, profitability, and control are embedded within the structure of global economics. Key firms such as Intel and Hewlett-Packard remain headquartered in Silicon Valley, even while their manufacturing operations are distributed around the world." $[19$, p. 13]. Even though high-technology equipment is mainly used in the core and semi-periphery, the lion's share of the production today have been moved to peripheral zones because of its hazardous nature and cheap labour and raw material. This is of course not only valid for the ICT industry but applies to many other industries such as the garment industry.

One the same topic, Frey [20] shows how health and environmental hazards are transferred to the periphery of the world system. Many governments in peripheral countries are willing to accept hazardous production processes and recycling of dangerous wastes such as ocean-going vessels, e-waste, and automobile batteries, in order to gain economic [21][22]. The economic earnings of these tradeoffs only affects a small portion of the peripheral country, i.e. those in power, while the negative effects affects the whole population.

Even though ICT is a fairly untouched area from a world systems analysis approach, several studies on environmental impact of ICT, in different stages of its value chain, have been carried out. In the next section, we are trying to present examples of unequal environmental exchange by the usage of ICT equipment.

\section{The Value Chain of ICT}

In this part, we are inspired by the value chain perspective on ICT hardware, meaning that we study ICT from materials extraction, to manufacturing, use, refurbish, reuse, and finally disposal. We believe that in order to apply WST, one must take a broad perspective on ICT. We know that there are several environmental implications throughout its value chain, including the extraction of scarce rare earth metals and dumping of electronic waste. We would like to consider these aspects in a geographical, political, social domain by turning to Alf Hornborg, and try to unravel where the positive aspects of IT are enjoyed and where the negative aspects of IT are situated geographically and why.

This part does not aim to be a systematic analysis and a proof that ICT leads to the unequal distribution of environmental effects. Rather, it is a collection of some examples of practices in the ICT value chain that are aimed to give an idea of what a thorough application of WST to ICT could lead to. Thus, the aim of the part is to indicate how the most positive benefits of ICT appears in the core countries, while the more negative impact appears in peripheral countries.

\subsection{Materials Extraction}

The production of ICT equipment depends on the supply of raw materials, and there has been a constant struggle to mine for many of these materials. Mining activities, including the extraction of materials needed to produce ICT are always linked to some kind of environmental destruction in the local environment. From a historical perspective, 
the mining for precious metals has caused severe damage to the landscape, with environmental consequences such as desertification, which is still present 2000 years after the original damage was caused [23]. Del Mar argues that wealth in Europe during both the Roman Empire and 1000 years later during the Middle Ages, was made possible by the exploitation of labour and natural resources outside of Europe, such as the Spanish raid and quest for gold in Latin America [23]. In today's terms we could argue that this can be compared with exploitation of Zambia by corporations such as Glencore, mining for copper [24], the permanent radioactive land in Malaysia, or the mercury polluted land in Brazil due to mining.

Large amounts of energy, either generated by muscular power or by combustion of fuel, are required in order to extract and crush and refine the metal ore. Processes like leaching uses highly toxic and/or cancerogenic chemicals such as fluor, mercury and arsenic. Large quantities of water for filtering are also used, which subsequently is deducted from the supply of available drinking water in the local area. Mining generates large amounts of waste, both useless rock that destroys the landscape visually, but also toxic waste that destroys the ecosystem. Extracting 1 ton of copper generates 600 tons of dangerous waste that somehow needs to be disposed of [24].

Rare Earth Elements, (REEs) are the elements needed to give electrical products certain properties, and very small amounts are needed in the electrical gadgets people use in their daily lives. REEs make it possible to produce energy efficient fluorescent light bulbs and add power-saving abilities in certain technological devices. But the energy saved in the core is paid with a high environmental and social price in the peripheral zones [25].

Conflict Minerals is another issue. The Democratic Republic of the Congo is a large producer of minerals used to produce ICT equipment. As one of the poorest countries in the world, yet a rich country in natural resource, the income generated by exporting minerals supports military rebels. Mining and smelting of coltan and the "three T's": tin, tantalum and tungsten [26] is often performed under slave-like conditions before transporting them to countries like China and India for production. Even though the core is aware of these conflicts, their dependency on coltan and other minerals for ICT products forces the core to turn the blind eye on the millions of death that mining directly or indirectly has caused in the periphery.

\subsection{Manufacturing}

The manufacturing of ICT equipment is linked with several social implications. Because this stage of the value chain requires a lot of manual labour, it is often outsourced to the periphery and the semi-periphery, due to the lack of regulation in these countries. What is less reflected upon is that the production phase is both very energy intensive as well as resource intense. Williams argues that the life cycle energy consumption of ICT equipment is dominated by production $(81 \%)$ as opposed to operation (19\%) [29]. James and Hopkinson state in the same book that "it is ... the case that when all impacts are considered, the materials and manufacturing stage probably has the greatest environmental impact" [29, p. 41]. Studies on notebooks show that the production phase, accounting for about $56 \%\left(214 \mathrm{~kg} \mathrm{CO}_{2} \mathrm{e}\right.$ in 5 years) of the total 
greenhouse gas emissions of the total life cycle, casts a significantly higher impact than the use phase. Moreover, the environmental impacts of the production phase of a notebook are so high, that they cannot be compensated in realistic time-periods by energy efficiency gains in the use phase. In the case of a $10 \%$ increase in the energy efficiency of a new notebook as compared to the older one in the use phase, replacement of the older notebook can only be justified after 33 to 89 years, if other environmental concerns than just the energy part is considered [30].

The production of ICT components is very water and resource intense. A study shows that the total amount of secondary fossil fuel and chemical input to the production of a $2 \mathrm{~g} 32 \mathrm{MB}$ DRAM chip is 1600 and $72 \mathrm{~g}$ respectively. One of these small components also requires 32000 liters of water to produce [49]. While the size of chips decreases, the used materials might actually increase [29].

Furthermore, in the new report "CSR issues in the ICT hardware manufacturing sector", the Centre for Research on Multinational Corporations (SOMO) focuses on an industry that has continuously moves to countries where production is cheaper, focusing predominantly on zones where labour rights and environmental issues have no to little priority. Research done for SOMO in China and the Philippines shows that computers are produced under endemic overtime, while the lack of unions and barriers to organizing means that the workers cannot negotiate for improvements. Workers are hired on short term contracts for years, blacklisted and subjected to discriminatory application processes [29].

\subsection{Use}

The use phase is where we can reap the benefits of ICT practices, according to recent reports $[1,28]$. While there are some obvious advantages in economic sustainability in the use phase, whether this phase can contribute to ecological sustainability globally is contentious. While some argue that ICT in the form of web meetings generates less need to travel and meet physically, others have argued that the number of physical meetings does not decrease [29].

It has been suggested that around $80 \%$ of energy consumption of PCs is in the production phase, as mentioned in the last section. However, a 2007 EU study by IVF reached the opposite. Their methodology suggests that $65 \%$ of the lifetime global warming impacts of a European office desktop computer are related to use the use phase, compared to $32 \%$ in production. The main reason for this is that although LCD monitors are lighter than CRTs, require less energy and resources in production, the latter can result in emissions of sulphur hexafluoride $\left(\mathrm{SF}_{6}\right)$ or nitrogen trifluoride $\left(\mathrm{NF}_{3}\right)$, which are very potent and long-lived greenhouse gases.

Kawamoto measured total energy use by office and network equipment as of 1999 , which amounted to $2 \%$ of the total electricity in the US [29]. Koomey shows that electricity consumption of Internet servers doubled in the period 2000-2005 [31]. Mills and Huber suggest that Internet absorbs some $8 \%$ of the total US electricity supply [32 p. 81]. 


\subsection{Refurbish and Reuse}

Some refurbishers of computers in Sweden have found a niche market in prolonging the life of computers by selling them second-hand to semi-peripheral countries before they actually become waste. The refurbisher refreshes software, tests batteries, erases hard drives and exchanges keyboards to fit the export market within the EU. They mainly sell proper second hand computers to former East Block countries. In Sweden the demand for second hand ICT equipment is very limited. Even though formal EU rules on e-waste recycling are the same, the likelihood for a machine to be fully recycled after its second life is far reduced in former East Block countries, since Sweden currently has the highest EU recycling rate in kilogram per person. Thus even though this is a fully legal operation, the risk for these machines not being recycled properly might increase by this step. On the other hand refurbishing is doubling the lifetime of the machine that delays production.

\subsection{Disposal}

The Basil Action Network (BAN) also estimates that Western electronic waste, primarily from the United States and the United Kingdom, is illegally exported to different countries in Southeast Asia and Africa. In 2005 BAN estimated that 275.000 tons of e-waste was being shipped to someone else's "backyard" [33]. This waste is not treated in any proper way and basically motherboards are melted over open fires releasing mercury fumes and dioxins of flame-retardants in order to extract precious metals such as gold and silver. Similar treatment is done with cables in order to extract copper.

The authors of Cradle to Cradle [ 32 p. 5] mention that copper waste ending up in regular household stream which end up in incinerating plants is getting melted into asphalt to a value of $£ 80$ million. Braungart claims that 15.000 tons of copper is being smelted into asphalt in Germany every year and thus being lost as a value resource that potentially could be fully recycled. The throwaway society in the core thus demands a continuation of supply from the periphery.

\subsection{Summary}

What could be indicated and what would also be the normative conclusions from WST in most of these examples is that most of the negative impacts of ICT along its value chain are displaced to peripheral zones. In the examples above, one can deduce that significant negative environmental impact is attributed in resource extraction, which is highly energy consuming, changes the natural environment, and is also detrimental to human well-being for the employees as well as for the local community. A part of electronic waste is also exported to peripheral regions such as parts of China, and Africa. The exported electronic waste has less economic value than the electronic waste that is recycled within the core areas such as the European Union. Rather, the electronic waste exported is that which requires low labour costs to process, such as cables, often burned outside in empty barrels, sometimes by children. Certainly 
peripheral areas also use ICT equipment, but it is probable that the ICT equipment used in these areas are not the newest nor best, but more often intermediate technology [51]. Peripheral areas do not benefit from ICT in the same ways as core regions, because of the constant race for speed and efficiency in this sector. Rather, peripheral areas presumably suffer from slow equipment and slow networks.

Manufacturing is often located in semi-peripheral regions, such as parts of China and India. Manufacturing is also an energy demanding and chemical intensive process. There have also been reports that the local environment is polluted to a large extent. Due to the fact that semi-peripheral regions are richer than peripheral regions, these regions probably enjoy more positive impacts of ICT than peripheral regions. However, the main benefits from ICT is expected to happen in core regions, where the newest smart systems and the latest gadgets are used. Hence, environmental issues boils down to energy issues only, which is indicated in for example Sustainable ICT literature (produced in the core), which is always almost exclusively focused on energy [34].

\section{Conclusions}

In this paper, we have presented the emergence of the IT trend Sustainable ICT and the claim that ICT can be a driving force in promoting a sustainable society. Moving from Green Computing to Green IT to Sustainable ICT, we have argued that the focus on the environmental effects of ICT is getting more and more positive. Green Computing emphasised reduction of energy use of ICT as well as more sustainable production of ICT. Green IT, with its bifurcation into Greening of IT and Greening by IT, can be said to both subsume Green Computing into Greening of IT, while also opening up for a more positive perspective of ICT with the concept of Greening by IT. At the same time, in the popular discourse, more attention is given to Greening by IT, that is, the positive perspective. Sustainable ICT broadens the perspective to not only environmental but also social and economic issues. Still, there is a focus on the positive aspects of ICT. If the discourse is analyzed from the perspective of Alf Hornborg, it is obvious that the discourse is one of cornucopia. ICT can, in this cornucopian view, solve a range of social issues, and the increasing penetration of ICT into various societal sectors is both desirable, and more importantly, possible.

In contrast to this optimistic view, we have presented WST, which argues that the discourse of cornucopia cannot be true. Rather, there is always a zero-sum game: if someone wins, someone must lose. We have reviewed WST, especially its ecological versions, and applied that to the ICT value chain. Thus, we have indicated how WST can be used to throw light on inequalities in the value chain, for example that core regions benefit most from the use of ICT while negative environmental impacts of ICT befalls peripheral regions. We have also brought up examples that problematize the strong focus on energy efficiency. Rather, one should also think about other environmental aspects of ICT.

Although we have drawn on WST in this paper, we do not unconditionally believe that it is correct. Rather, what we have been trying to do is to introduce an alternative, 
or minor, discourse to the one-sided discourse that is being promoted by dominant actors in the industry (such as large companies). When discussing the sustainability of ICT, one should thus consider both the arguments from the discourses of cornucopia and zero-sum game.

\section{References}

1. Global e-Sustainability Initiative (GeSI), SMART 2020: Enabling the Low Carbon Economy in the Information Age, http: / /www. theclimategroup.org/assets / resources / publications / Smart2020Report.pdf

2. Fehske, A., Fettweis, G., Malmodin, J., Biczok, G.: The global footprint of mobile communications: The ecological and economic perspective. IEEE Communications Magazine 49(8), 55-62 (2011)

3. CEPT ECC PT1 International Report on Mobile Broadband Landscape (2011), http: / / www . cept.org/files/4549/ECC\%20PT1\%20internal\% 20 report $\% 20$ on $\% 2$ MBB $\% 20-\% 20 \mathrm{ECC} \% 20 \mathrm{PT} 111162 \% 20$ Annex 2023 . docX

4. Hornborg, A.: Global ecology and unequal exchange: Fetishism in a zero-sum world (2011)

5. Hornborg, A., Jorgensen, A.K.: International trade and environmental justice: Toward a global political ecology. Nova Science Publishers (2010)

6. Hopkins, T.K., Wallerstein, I., Bach, R.L.: World-systems analysis: theory and methodology, p. 47. Sage Publications, Beverley Hills (1982)

7. Erdmann, L., Hilty, L.M.: Scenario Analysis. Journal of Industrial Ecology 14(5), 826-843 (2010)

8. Yi, L., Thomas, H.R.: A review of research on the environmental impact of e-business and ICT. Environment International 33(6), 841-849 (2007)

9. Ruth, S.: Green it more than a three percent solution? IEEE Internet Computing 13(4), 74-78 (2009)

10. Fors, P., Lennerfors, T.T.: Translating Green IT: The case of the Swedish Green IT Audit. In: Hilty, L.M., Aebischer, B., Andersson, G., Lohmann, W. (eds.) CT4S 2013: Proceedings of the First International Conference on Information and Communication Technologies for Sustainability, ETH Zurich, February 14-16, pp. 208-216 (2013)

11. Harmon, R.R., Demirkan, H.: The Next Wave of Sustainable IT. IEEE Computer Society IT Professional, 19-25 (January/February 2011); Lead article

12. Wallerstein, I.: World-systems analysis: An introduction. Duke University Press (2004)

13. Chirot, D., Hall, T.D.: World-system theory. Annual Review of Sociology 8, 81-106 (1982)

14. Hornborg, A.: The power of the machine: Global inequalities of economy, technology, and the environment, vol. 1. Rowman Altamira (2001)

15. Odum, H.T., Arding, J.E.: Emergy analysis of shrimp mariculture in Ecuador, p. 114. The Center (1991)

16. Konieczny, P.: The Internet and the world-system (s). In: Routledge International Handbook of World-Systems Analysis, p. 260 (2012)

17. Nelson-Richards, et al.: Routledge International Handbook of World-Systems Analysis (2012)

18. Lawrence, et al.: Routledge International Handbook of World-Systems Analysis (2012)

19. Smith, T., Sonnenfeld, D.A., Pellow, D.N. (eds.): Challenging the chip: Labor rights and environmental justice in the global electronics industry. Temple University Press (2006) 
20. Frey, R.S.: The transfer of core-based hazardous production processes to the export processing zones of the periphery: The maquiladora centers of northern Mexico. Journal of World-Systems Research 9(2), 317-354 (2003)

21. Buerk, R.: Breaking Ships: How supertankers and cargo ships are dismantled on the shores of Bangladesh. Chamberlain Brothers, p. 192 (2006) ISBN 1-59609-036-7

22. Frey, R.S.: The transfer of core-based hazardous production processes to the export processing zones of the periphery: The maquiladora centers of northern Mexico. Journal of World-Systems Research 9(2), 317-354 (2003)

23. Del Mar, A.: A History of the Precious Metals, from the earliest times to the present. British Library, Historical Print Edition, London (1880)

24. Gulbrandsen, C.: Stealing Africa - Why Poverty? (Motion Picture) (2012)

25. Pitron, G., Turquier, S.: La sale guerre des terres rares (Motion Picture) (2012)

26. Eichstaedt, P.: Consuming the Congo, war and conflict minerals in the world's deadliest place. Lawrence Hill Books, Chicago (2011)

27. Prakash, S., Liu, R., Schischke, K., Stobbe, L.: Timely replacement of a notebook under consideration of environmental aspects. Umweltbundesamt (2012)

28. Gartner, The Data Center Power and Cooling Challenge, David Cappuccio and Lynne Craver (November 2007)

29. Rattle, R.: Computing Our Way to Paradise?: The Role of Internet and Communication Technologies in Sustainable Consumption and Globalization. Rowman \& Littlefield (2010)

30. Prakash, S., Liu, R., Schischke, K., Stobbe, L.: Timely replacement of a notebook under consideration of environmental aspects. Umweltbundesamt (2012)

31. Kostigen, T.: The Underbelly of Globalization: Our Toxic Wastes Exported to Developing Countries (September 25, 2008) Basil Action Network - Library, http: / /ban.org/library/Features /080925_the_underbelly_of_ globalization.html (retrieved December 11, 2013)

32. McDonough, W., Braungart, M.: Cradle to Cradle. Vintage, Croydon (2009)

33. Sonhüter, B., Liebsch, M. (Directors): Nie mehr Müll - Leben ohne Abfall (Motion Picture) (2010)

34. Yotsumoto, M., Lennerfors, T.T., Majima, T.: The current trends and issues of Green IT. In: The Japan Association for Management Information (JASMIN) Conference, Japan, October 29-30 (2011) 